\title{
COVID and the Caregiver
}

\author{
David Walsh, MDD
}

Medical College of Georgia at Augusta University, Augusta, GA, USA.

\section{$\mathrm{H}$} ammering fear pounds

Blankets of courage hurtle

Breath to breath we dance

Corresponding Author: David Walsh, MD, Medical College of Georgia at Augusta University, Augusta, GA, USA (email:dawalsh@augusta.edu).

$\mathrm{J}$ Gen Intern Med 36(1):224

DOI: $10.1007 / \mathrm{s} 11606-020-06301-3$

(c) Society of General Internal Medicine 2020

Publisher's Note: Springer Nature remains neutral with regard to jurisdictional claims in published maps and institutional affiliations.

Received June 4, 2020

Accepted October 6, 2020

Published online October 26, 2020 